\title{
"Escrevivência" em Becos da memória, de Conceição Evaristo
}

\section{Becos da memória.}

EVARISTO, Conceição.

Belo Horizonte: Mazza, 2006.

"Homens, mulheres, crianças que se amontoaram dentro de mim, como amontoados eram os barracos de minha favela" (p. 21).

Evaristo, 2006, p. 21.

Maria da Conceição Evaristo de Brito nasceu em Belo Horizonte, em 1946. De origem humilde, migrou para o Rio de Janeiro na década de 1970. Graduou-se em Letras pela UFRJ, trabalhou como professora da rede pública de ensino da capital fluminense e da rede privada de ensino superior. É mestre em Literatura Brasileira pela PUC-Rio. No momento, está concluindo doutorado em Literatura Comparada na Universidade Federal Fluminense. Em sua pesquisa, estuda as relações entre a literatura afro-brasileira e as literaturas africanas de língua portuguesa. Participante ativa dos movimentos de valorização da cultura negra em nosso país, estreou na arte da palavra em 1990 , quando passou a publicar seus contos e poemas na série Cadernos Negros, suporte de que se utiliza até hoje.

Em 2003, veio a público o romance Ponciá Vicêncio, pela editora Mazza, de Belo Horizonte. Seu segundo livro, outro romance, Becos da memória, foi escrito em fins dos anos 1970 e início dos 1980. Ficou engavetado por cerca de 20 anos até sua publicação, em 2006. Desde então, os textos de Evaristo vêm angariando cada vez mais leitores, sobretudo após a indicação de seu primeiro livro como leitura obrigatória do Vestibular da UFMG, em 2007. A escritora participou ainda de publicações coletivas na Alemanha, na Inglaterra e nos Estados Unidos. Sua obra de estreia foi traduzida para o inglês e está em processo de tradução para o espanhol.

A obra em prosa de Conceição Evaristo é habitada, sobretudo, por excluídos sociais, dentre eles favelados, meninos e meninas de rua, mendigos, desempregados, beberrões, prostitutas, "vadios" etc., o que ajuda a compor um quadro de determinada parcela social que se relaciona de modo ora tenso, ora ameno, com o outro lado da esfera, composta de empresários, senhoras de posses, policiais, funcionários do governo, dentre outros. Personagens como Di Lixão, Duzu-Querença, Ana Davenga e Natalina, presentes no universo dos contos publicados nos Cadernos Negros; Ponciá Vicêncio, Vô Vicêncio, Luandi, Nêngua Kainda, Zé Moreira, Bilisa e Negro Glimério, listados em Ponciá Vicêncio; Maria-Nova (desdobramento ficcional da autora?), Maria Velha, Vó Rita, Negro Alírio, Bondade, Ditinha, Balbina, Filó Gazogênia, Cidinha-Cidoca, Tio Totó e Negra Tuína, de Becos da memória, exemplificam, no plano da ficção, o universo marginal que a sociedade tenta ocultar.

Becos da memória é marcado por uma intensa dramaticidade, o que desvela o intuito de transpor para a literatura toda a tensão inerente ao cotidiano dos que estão permanentemente submetidos à violência em suas diversas modalidades. Barracos e calçadas, bordéis e delegacias compõem o cenário urbano com que se defrontam os excluídos de todos os matizes e gradações, o que insinua ao leitor qual a cor da pobreza brasileira. No entanto, a autora escapa das soluções fáceis: não faz do morro território de glamour e fetiche; tampouco, investe no traço simples do realismo brutal, o qual acaba transformando a violência em produto comercial para a sedenta sociedade de consumo.

Os fragmentos que compõem Becos da memória procuram aliar a denúncia social a um lirismo de tom trágico, o que remonta ao mundo íntimo dos humilhados e ofendidos, tomados no livro como pessoas sensíveis, marcadas, portanto, não apenas pelos traumas da exclusão, mas também por desejos, sonhos e lembranças. Violência e intimismo, realismo e ternura, além de impactarem o leitor, revelam o compromisso e a identificação da intelectualidade afrodescendente com aqueles colocados à margem do que o discurso neoliberal chama de progresso.

Sabendo que é possível à obra (re)construir a vida, através de "pontes metafóricas", pelo 
projeto literário de Conceição Evaristo vislumbram-se pistas de possíveis percursos e leituras de cunho biográfico. Na configuração do romance em questão pululam aqui e ali, ora na ficção, ora em entrevistas, ora em textos acadêmicos, peças para a montagem de seu quebra-cabeça literário e biográfico. Uma das peças desse jogo parece ser a natureza da relação contratual estabelecida entre o leitor e o espaço autoficcional em que se insere Becos da memória. Aqui, a figura autoral ajuda a criar imagens de outra(s) Evaristo(s), projetada(s) em seus personagens, como Maria-Nova, por exemplo. Em outras palavras, processa-se uma espécie de exercício de elasticidade de um eu-central. Desliza-se com facilidade na prosa de Evaristo entre o romance e a escrita de si. Se, tradicionalmente, aquele se preocupa com o universal humano e esta, com o particular ou com o indivíduo, a autora propõe a junção dos dois gêneros, pois, para ela, pensar a si é também pensar seu coletivo. Do ponto de vista formal não é diferente: não se utilizam capítulos, mas fragmentos, bem a gosto do narrador popular benjaminiano. Nessa perspectiva, vêse o mundo através da ótica dos fragmentos e dos indivíduos anônimos que compõem boa parte da teia social.

Neste livro de corte tanto biográfico quanto memorialístico, nota-se o que a autora chama de escrevivência, ou seja, a escrita de um corpo, de uma condição, de uma experiência negra no Brasil. Tanto na vida da autora quanto em Becos da memória, a leitura antecede e nutre as escritas de Evaristo e de Maria-Nova, razão pela qual lutam contra a existência em condições desfavoráveis. Ler é também arquivar a si, pois se selecionam momentos e estratégias de elaboração do passado, o qual compõe as cenas vividas, escritas e recriadas em muitos de seus personagens. Finalmente, decodificar o universo das palavras, para a autora e para MariaNova, torna-se uma maneira de suportar o mundo, o que proporciona um duplo movimento de fuga e inserção no espaço. Não menos importante, a escrita também abarca estas duas possibilidades: evadir para sonhar e inserir-se para modificar.

O lugar de enunciação mostra-se solidário e identificado com os menos favorecidos, vale dizer, sobretudo, com o universo das mulheres negras. E o universo do sujeito autoral parece ser recriado através das caracterizações físicas, psicológicas, sociais e econômicas de suas personagens do gênero feminino. Maria-Nova, presente em Becos da memória, aos nossos olhos, compõe-se, mais do que todas as personagens, de rastros do sujeito autoral: menina, negra, habitante durante a infância de uma favela e que vê na escrita uma forma de expressão e resistência à sorte de seu existir. Uma ponte metafórica que arriscamos instalar permite ver em comum, ainda, o fato de serem provenientes de famílias sustentadas por matriarcas lavadeiras, transitantes entre os mundos da prosperidade e da miséria, ou seja, Conceição e MariaNova cumpriram, no espaço familiar em que estiveram, o papel de mediação cultural que aperfeiçoou o processo de bildung (confirma palavra em inglês?) de uma e de outra.

A obra se constrói, então, a partir de "rastros" fornecidos por aqueles três elementos formadores da escrevivência: corpo, condição e experiência. $O$ primeiro elemento reporta à dimensão subjetiva do existir negro, arquivado na pele e na luta constante por afirmação e reversão de estereótipos. A representação do corpo funciona como ato sintomático de resistência e arquivo de impressões que a vida confere. O segundo elemento, a condição, aponta para um processo enunciativo fraterno e compreensivo com as várias personagens que povoam a obra. A experiência, por sua vez, funciona tanto como recurso estético quanto de construção retórica, a fim de atribuir credibilidade e poder de persuasão à narrativa. No livro em questão, a voz enunciativa, num tom de oralidade e reminiscência, desfia situações, senão verdadeiras, verossimilhantes, ocorridas no "morro do Pindura Saia", espaço que bem se assemelha ao da infância da autora. Arriscamos dizer que há "jogo especular", portanto, entre a experiência do sujeito empírico e de MariaNova, para além da simetria do espaço da narrativa (favela) e do espaço da infância e da juventude da autora (idem).

Outro bom exemplo de jogo especular consiste em uma situação por que realmente passou Evaristo e que se repete com Maria-Nova. Aliás, tem sido realmente um verdadeiro trauma para crianças negras estudar na escola tópicos relativos à escravidão e seus desdobramentos. Enquanto a professora se limitava à leitura de um conteúdo abstrato e com visão eurocêntrica acerca do passado escravocrata, Maria-Nova não conseguia enxergar naquele ato - e na escola - sentido para a concretude daquele assunto. Afinal, ela e a autora viviam e sentiam na pele as consequências da exploração do homem pelo homem na terra brasilis. Sujeitomulher-negra, abandonada à própria sorte a partir do dia 14 de maio de 1888 , 
Maria-Nova olhou novamente a professora e a turma. Era uma história muito grande! Uma história viva que nascia das pessoas, do hoje, do agora. Era diferente de ler aquele texto. Assentou-se e, pela primeira vez, veio-lhe um pensamento: quem sabe escreveria esta história um dia? Quem sabe passaria para o papel o que estava escrito, cravado e gravado no seu corpo, na sua alma, na sua mente ( $p$. 138).

A garota, ciente de que a história das lutas dos negros no Brasil começava já com as primeiras levas diaspóricas, parece repetir o célebre questionamento de Gayatri Spivac: "pode o subalterno falar?". Mais que isso: falar, ser ouvido, redigir outra história, outra versão, outra epistemologia, que leve em conta não o arquivamento das versões dos vencidos, mas que valorize o sujeito comum, anônimo, do dia a dia. Talvez Maria-Nova nem tenha se dado conta de que o que ela havia pensado era exatamente a fundamentação de boa parte dos Estudos Pós-Coloniais e da História Nova. Nesse sentido, os corpos-textos de Maria-Nova e Conceição Evaristo possuem em comum a missão política de inventar outro futuro para si e para seu coletivo, o que lhes imbui de uma espécie de dever de memória e dever de escrita. Vejamos: "agora ela [Maria-Nova] já sabia qual seria a sua ferramenta, a escrita. Um dia, ela haveria de narrar, de fazer soar, de soltar as vozes, os murmúrios, os silêncios, o grito abafado que existia, que era de cada um e de todos. Maria-Nova, um dia, escreveria a fala de seu povo (p. 161).

E a escrita acompanhará a pequena até a última página do livro, o que nos permite pensar que a missão ainda está em processo: "não, ela [Maria-Nova] jamais deixaria a vida passar daquela forma tão disforme. [...] Era preciso viver. 'Viver do viver'. [...] O pensamento veio rápido e claro como um raio. Um dia ela iria tudo escrever" (p. 147).

E escreveu em seu mundo de papel. Coube a Evaristo registrar o desejo de MariaNova e, logo, seu próprio desejo. O desdobramento de uma em outra e as pontes metafóricas que pretendemos instaurar não esgotam as possibilidades de leituras, mas permitem a possibilidade de muitas outras, que despertem o afã de também escrever.

Luiz Henrique Silva de Oliveira Universidade Federal de Minas Gerais 